\title{
Immunological Role of Vitamin D in Skin Diseases and Carcinoma
}

\author{
Kelley Yuan ${ }^{1}$, Chikezie O. Madu²,3, Yi Lu ${ }^{3 凶}$ \\ 1. Department of Biology and Advanced Placement Biology, White Station High School, Memphis, Tennessee 38117. USA. \\ 2. Department of Biology and Advanced Placement Biology, White Station High School, Memphis, Tennessee 38117. USA. \\ 3. Department of Pathology and Laboratory Medicine, University of Tennessee Health Science Center, Memphis, TN 38163, USA.
}

$\triangle$ Corresponding author: Yi Lu, Ph.D., Department of Pathology and Laboratory Medicine, University of Tennessee Health Science Center, Cancer Research Building, Room 218, 19 South Manassas Street, Memphis, TN 38163, USA. Tel: (901) 448-5436; Fax: (901) 448-5496; e-mail: ylu@uthsc.edu.

(C) Ivyspring International Publisher. This is an open access article distributed under the terms of the Creative Commons Attribution (CC BY-NC) license (https://creativecommons.org/licenses/by-nc/4.0/). See http://ivyspring.com/terms for full terms and conditions.

Received: 2017.01.19; Accepted: 2017.01.29; Published: 2017.03.08

\begin{abstract}
Growing evidence attests to the vital role vitamin $D$ plays in the dynamics of the immune system. Active $1,25(\mathrm{OH})_{2} \mathrm{D}_{3}$ binds to the vitamin $\mathrm{D}$ receptor (VDR) to form a ligand-activated receptor complex able to control transcription in the nucleus. We examined the various mechanisms through which vitamin $\mathrm{D}_{3}$ alters and enhances immune responses in a variety of skin conditions, as well as the pathways it activates to inhibit the progression of tumors and carcinomas. The hormone primarily elicits a change as either an inflammation modulator or cancer suppressor. Also addressed are current advancements in vitamin D treatment methods through the development of novel analogs.
\end{abstract}

Key words: Vitamin D, Skin Diseases, Carcinoma

\section{Introduction}

Vitamin D synthesis begins with the cutaneous precursor 7-dehydrocholesterol. After absorbing UVB radiation, $7-\mathrm{DHC}$ is converted to pre-vitamin $\mathrm{D}_{3}$, which further reconfigures into cholecalciferol. Lipid-soluble cholecalciferol then proceeds to either adipocytes for storage or to the liver, where 25-hydroxylase converts the compound to calcidiol or serum-25(OH)D. To become the activated form of vitamin $\mathrm{D}$, calcidiol must be hydroxylated again by a second 1-alpha hydroxylase (CYP27B1), expressed abundantly in the skin and kidneys, to calcitriol or $1,25(\mathrm{OH})_{2} \mathrm{D}_{3}$. This active form binds with the vitamin $\mathrm{D}$ receptor (VDR) to effectuate a host of transcriptional pathways. Once a vitamin $\mathrm{D}$ response has completed, 25- hydroxyvitamin D-24-hydroxylase (CYP24) renders both serum-25(OH)D and $1,25(\mathrm{OH})_{2} \mathrm{D}_{3}$ inactive as hydrophilic calcitroic acid to terminate the vitamin D/VDR pathway. [1] Vitamin D primarily maintains the skeleton and mineral metabolism by enhancing calcium absorption in both bone tissue and the intestinal tract. This aid in calcium uptake promotes osteoclast differentiation and improves bone matrix mineralization. [2] The vitamin $\mathrm{D}$ receptor is present in the nuclei of various immune cells. Volumes of studies have shown that vitamin $\mathrm{D}_{3}$ modulates both the innate and adaptive immune responses by governing lymphocyte activation, survival, differentiation, and maturation. Active $1,25(\mathrm{OH})_{2} \mathrm{D}_{3}$ functions overall as both an inflammatory modulator and cancer suppressor.

\section{Vitamin D in the Immune System}

Part of innate immunity, dendritic cells are antigen-presenting cells (APC) critical in initiating the $\mathrm{CD}^{+} \mathrm{T}$ cell response. Inflammatory stimuli such as lipopolysaccharides (LPS) trigger dendritic cell maturation, which compromises their antigen-capturing ability for an increase in their 
co-stimulatory capacity for T cell activation. [3] Initial exposure of dendritic cells to inflammatory antigens boost the synthesis of loaded class II MHC molecules with extended half lives, with the ability to activate $\mathrm{T}$ cells over a span of multiple days.

$1,25(\mathrm{OH})_{2} \mathrm{D}_{3} \quad$ inhibits this LPS-induced maturation by maintaining the immature dendritic cell phenotype, characterized by high mannose receptor expression and low CD83 expression. Meanwhile, it significantly reduces the production of co-stimulatory molecules CD40, CD80, and CD86 and of class II MHC molecules needed for dendritic cells to stimulate alloreactive $\mathrm{T}$ cells. [4] Vitamin D also hinders adult cell activity by promoting apoptosis in mature dendritic cells and reducing their production of interleukin 12 (IL-12), a key cytokine generated by $B$ cells and monocytes necessary for T-helper 1 cell development. [5]

Vitamin $\mathrm{D}_{3}$ impacts adaptive immune lymphocytes as well. Central to the adaptive immune network are T-helper cells. T-helper 1 (Th1) cells are a subset of $\mathrm{CD}^{+}$effector T-cells associated with adaptive cellular immune responses. $1,25(\mathrm{OH})_{2} \mathrm{D}_{3}$ suppresses Th1 function by suppressing gamma interferon (IFN- $\gamma$ ), inhibiting Th1-induced IgG2a activity. [6]

Another group of interleukin-17 (IL-17)-producing helper $\mathrm{T}$ cells (Th17 cells) are believed to drive the inflammatory tissue injury in several autoimmune pathological processes because they are often present at the sites of tissue inflammation in autoimmune diseases. [7] Further research points to the role active vitamin $\mathrm{D}_{3}$ plays in autoimmune diseases through its control of the interleukins attributed to the disorders. $1,25(\mathrm{OH})_{2} \mathrm{D}_{3}$ halts the expression of IL-17A in both human and mouse Th17 cells. The VDR receptor complex mediates the transcriptional repression by reducing Runt-related transcription factor 1 (Runx1), inducing Foxp3 production. [8]

This hormone also inhibits IL-17A production in the $\mathrm{T}$ cells of both multiple sclerosis and early rheumatoid arthritis patients. [9] IL-17 production and $\gamma$ interferon production by Th17 cells of both control groups and those with multiple sclerosis declined after the cells were treated with vitamin D. The declines in cytokine levels occurred because $\mathrm{T}$ cells constitutively express CYP27B1, the gene encoding 1a-hydroxylase, and are therefore able to produce active vitamin $\mathrm{D}$ from a $25(\mathrm{OH}) \mathrm{D}_{3}$ precursor. [10] In addition to impacting $\mathrm{T}$ cells, vitamin $\mathrm{D}_{3}$ has been shown to suppress proliferation and immunoglobulin production in a range of normal human peripheral blood mononuclear cells. [11]

$B$ cells, another branch of the secondary immune response, are antigen-presenting cells capable of activating lymphocytes and preserving immunological memory. In a different experiment on cells from patients with autoimmune lupus erythematosus, vitamin $\mathrm{D}_{3}$ was capable of stimulating apoptosis in activated $\mathrm{B}$ cells in addition to suppressing their proliferation. It also halted the differentiation of plasma cells. Research suggests vitamin $\mathrm{D}_{3}$ controls this essential $\mathrm{B}$ cell homeostasis by increasing p27 expression without impacting p18 and p21 expression, making it a strong candidate for treating B-cell associated autoimmune diseases. [12] Notably, pre-incubating cells with 1,25-vitamin $\mathrm{D}_{3}$ considerably decreases both spontaneous and stimulated immunoglobulin production in B cells of active lupus patients. [13]

A subpopulation of $\mathrm{T}$ lymphocytes, regulatory $\mathrm{T}$ cells (Foxp3+ Tregs) maintain immune tolerance and safeguard against autoimmune reactions by removing self-reactive T cells. Tregs may be naturally produced or induced by chemokines, predominantly by the expression of Foxp3 ${ }^{+}$. Mounting research exploring Treg interactions are elucidating not only the impact of Treg dysfunction in normal immune function, but also its interaction with vitamin $\mathrm{D}_{3}$. [14]

In activated $\mathrm{CD} 4{ }^{+} \mathrm{CD} 25^{-}$Treg cells, vitamin $\mathrm{D}_{3}$ inhibits the production of pro-inflammatory cytokines including IFN- $\gamma$ and IL-17. In the presence of IL-2, it upregulates the expression of CTLA- 4 and Foxp3 ${ }^{+}$. T cells that were treated with $1,25(\mathrm{OH})_{2} \mathrm{D}_{3}$ possessed characteristics of adaptive regulatory $\mathrm{T}$ cells because they were able to repress the proliferation of normally responsive T cells. Therefore, IL-2 and active vitamin $\mathrm{D}_{3}$ are suspected to synergistically interact as both inducers of adaptive Tregs and potent suppressors of inflammation. [15] Results from a different study reveal that active vitamin $\mathrm{D}_{3}$ alone can enhance the potency of human natural regulatory $\mathrm{T}$ cells (nTregs). By upregulating Foxp3 $3^{+}$and intervening in the cell cycle, active vitamin $D_{3}$ serves as a catalyst that amplifies Treg suppressive efficiency. [16] A recent study by Gorman et al confirms these observations, reporting dietary vitamin $\mathrm{D}_{3}$ inducing Treg cell proliferation in the skin-draining lymph nodes, spleen, and blood and increasing their suppressive capacity against dermal inflammation. [17]

In addition, when administered with immunosuppressive glucocorticoids, $1,25(\mathrm{OH})_{2} \mathrm{D}_{3}$ stimulated the production of a homogeneous generation of $\mathrm{CD} 4^{+} / \mathrm{CD} 25^{+}$Tregs in vitro that produce IL-10. These cells IL-10-dependently repress inflammation in the central nervous system, providing a promising outlook for Treg application in immunotherapy. [18]

Overall, the hormone generally enhances the 
innate branch and suppresses the adaptive branch. These controlled and differentiated pathways prove vitamin $\mathrm{D}^{\prime} \mathrm{s}$ critical role in modulating immune responses (Figure 1).

\section{Vitamin D as an Inflammatory and Transcriptional Modulator}

It is known that vitamin $\mathrm{D}_{3}$ ameliorates inflammation by repressing pro-inflammatory cytokine production in Treg cells. However, its anti-inflammatory effect also arises from its ability to modulate the release of autocrine and paracrine repair factors in fibroblasts - cells integral to the tissue repair process that often dysfunction in asthma and chronic obstructive pulmonary disorder (COPD). Serum $25(\mathrm{OH}) \mathrm{D}$ and $1,25(\mathrm{OH})_{2} \mathrm{D}_{3}$ both drastically reduce pro-inflammatory prostaglandin (PG)E2 synthesis in human lung fibroblasts, and both also decrease IL-1 $\beta$-induced microsomal PGE synthase (mPGES)-1 expression. Moreover, both forms could effectively stimulate 15-hydroxy PG dehydrogenase, the enzyme responsible for degrading PGE2 and thus terminating the inflammatory reaction. Through this pathway, vitamin $\mathrm{D}$ could enhance fibroblast-involved tissue repairs. [19]

COX-2, an isoform of inducible cyclooxygenase (COX), plays a role in chronic inflammatory disorders by generating the family of prostanoids that enhance inflammation. Activated vitamin $\mathrm{D}_{3}$ has been found to dose-dependently limit the expression of both COX-2 and LPS-induced pro-inflammatory particles in murine macrophages, effectively reducing regional inflammation in murine edema. Studies illustrate that vitamin $\mathrm{D}$ silences the Akt/NF-kB/COX-2 pathway, which reduces macrophage-involved inflammation. [20] Vitamin $\mathrm{D}_{3}$ also dampens the inflammatory response further by repressing the production of prostaglandin receptors responsible for communicating the inflammatory message. [21]

Though activated $1,25(\mathrm{OH})_{2} \mathrm{D}_{3}$ is involved in numerous signaling mechanism, it also impacts the immune system upstream by modulating transcription. The hormone binds to the nuclear ligand-activated vitamin $\mathrm{D}$ receptor (VDR). This receptor complex, with additional co-regulatory proteins, forms a heterodimer with the retinoid $X$ receptor (RXR) and stimulates vitamin $\mathrm{D}$ response elements (VDREs)-distinct promoter regions of target gene DNA - to upregulate gene expression. [22] VDR complexes have been shown to bind with VDREs located in the genes of IL-10, IL-2, and IL-12B to downregulate the expression of these genes in LPS-treated human monocytes. Because each of these genes share common VDREs that recruit the receptor complex, the transcription of these listed cytokines may be governed directly by activated vitamin $\mathrm{D}_{3}$. [23]

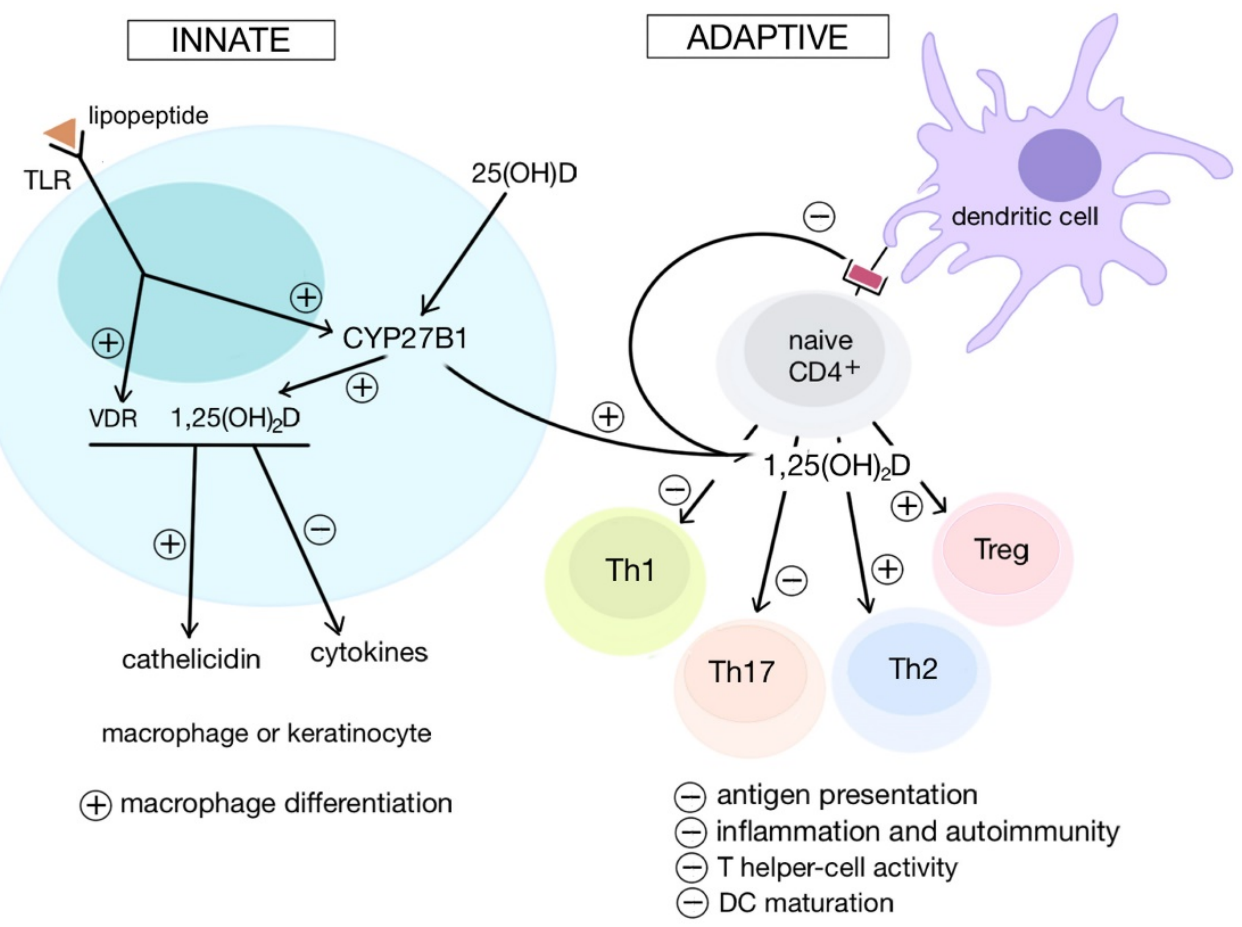

Figure 1. Illustration of the changes that vitamin D elicits in both the innate and adaptive branches of the immune system. Generally, vitamin $D$ enhances innate immunity by promoting macrophage differentiation and the production of various chemokines. In contrast, the adaptive immune system is repressed. Vitamin $D$ inhibits the antigen-presenting abilities of certain cells and upregulates $T$ regulatory cell levels to stifle $T$ cell proliferation. In this manner vitamin D combats inflammation and autoimmune responses. 
Vitamin $\mathrm{D}_{3}$ also changes the expression of target genes in immune cells by regulating transcription factors such as the constitutively-expressed nuclear factor kappa B (NF-kB) protein complex. In the presence of vitamin $D_{3}$, the levels of both the factor and its precursor dropped. In addition, vitamin $\mathrm{D}_{3}$ triggers signaling pathways such as the Janus kinase-signal transducer and activator of transcription. These transcription factor dynamics reveal that NF-kB de novo synthesis occurs during the activation of lymphocytes and is potentially directed by hormone interactions. [24] Repeated trials reveal that $1,25(\mathrm{OH})_{2} \mathrm{D}_{3}$ downregulates the NF-kB levels in activated human lymphocytes. [24] Its inhibitor, ІкB, localizes the inactive form of NF-KB in the cytosol to prevent its natural localization sequences from being recognized for transport into the nucleus. After pro-inflammatory stimuli impact the cell, IKB is phosphorylated and subsequently ubiquitinyated before becoming degraded by a proteasome. Subsequently, freed NF-kB factors travel to the nucleus and activate the transcription of pro-inflammatory cytokines and enzymes that synthesize pro-inflammatory mediators such as COX-2. [25]

A study conducted by Zhang et al. identified mitogen-activated protein kinase phosphatase-1 (MKP-1) as a novel vitamin D pathway that suppresses LPS-induced p38 activation and regulates human monocyte production of pro-inflammatory cytokines IL- 6 and TNF-a. This effect was marked by active histone $\mathrm{H} 4$ acetylation at certain VDREs in MKP1 promoter locations. [26] Similar experiments have found that $1,25(\mathrm{OH})_{2} \mathrm{D}_{3}$ also upregulates mitogen kinase phosphatase MKP-5, leading to the same inactivation of the p38 kinase pathway and the subsequent decrease in the synthesis of pro-inflammatory IL-6. [21]

\section{Immune-Mediated Disorders and the Role of Vitamin D in Their Progression and Treatment}

Psoriasis, a hyperproliferative skin disease, is characterized by red, itchy patches often found on the outer face of joints. Psoriatic lesions are thick and erythematous plaques covered by flaky, silvery scales. Histological features are characterized by increased proliferation of keratinocytes and leukocytes in the epidermis, a large number of infiltrated inflammatory cells in the dermis, and increased vasculatures. [27] The condition is still of unknown etiology, for the antigens activating psoriatic $\mathrm{T}$ cells have still not been confirmed. Initially, psoriasis was attributed solely to autoreactive Th1 and Th17 cells because the plaques included high levels of IL-12, IL-22, IL-26, and TNF-a, the characteristic chemokines of helper T cells. $[28,29]$ However, also present in the lesions were elevated levels of IL-23, the product of dendritic cells and certain macrophages. [30]

Extensive studies sufficiently substantiate the role of the Th17 cell in the pathogenesis of psoriasis. Naïve CD4 T cells differentiate into Th17 cells after they are activated by the antigens of antigen-presenting dendritic cells. Th17 cells then migrate to the skin after their chemokine receptors are expressed and bound with ligands. Cytokines, such as IL-23, derived from antigen-presenting cells activate Th17 cells to produce IL-17 cytokines. IL-17 cytokines further generate inflammation by activating stromal cells to produce other inflammatory mediators. [31]

The epidermal layer of the skin houses a thick network of a unique subset of dendritic cells called Langerhans cells. $1,25(\mathrm{OH})_{2} \mathrm{D}_{3}$ effectively prevents human skin Langerhans cells from stimulating antigen-dependent $\mathrm{T}$-cells and triggering their proliferation. Therefore, vitamin $\mathrm{D}$ may be responsible for skin immunosuppression. [32] Successive studies tracked the production of cytokines of T-cell clones from psoriatic skin samples post-activation. Vitamin $\mathrm{D}_{3}$ inhibited $\mathrm{T}$ cell proliferation and blocked the synthesis of Th1 chemokines IFN-y, IL-2, IL-4, and IL-5. Therefore, the results propose that active vitamin $\mathrm{D}_{3}$ combats psoriasis by halting the proliferation and cytokine activity of T lymphocytes stationed in the skin. [33]

Significant results by Grishkan et al provide several landmark observations regarding helper $\mathrm{T}$ cells in multiple sclerosis, opening many methods to combatting autoimmune diseases. In a murine EAE (experimental autoimmune encephalomyelitis) model, vitamin $\mathrm{D}_{3}$ prevents encephalitogenic $\mathrm{T}$ cells from breaching the CNS without impacting their activation. Additionally, $1,25(\mathrm{OH})_{2} \mathrm{D}_{3}$ sustains leukocytosis without inducing the development of $\mathrm{T}$ regulatory cells or confining Th cells to the lymph nodes. $\mathrm{T}$ cells of $1,25(\mathrm{OH})_{2} \mathrm{D}_{3}$-treated mice were unable to cross the blood-brain barrier, a key target vehicle of encephalitis. Because $1,25(\mathrm{OH})_{2} \mathrm{D}_{3}$ repression of $\mathrm{EAE}$ is reversible when treatment ceases, the data indicates that active vitamin $\mathrm{D}_{3}$ might influence a target with rapid turnover, notably pathogenic T cells. [34]

Atopic dermatitis or eczema is another chronic inflammatory skin disease, producing splotchy, raised lesions lining the inside of joints and along the arms, legs, and neck. The skin lesions are characterized by prominent infiltrates of mononuclear cells in the 
dermis and intercellular edema in the epidermis. Clinical studies indicate that oral vitamin D supplements dramatically ameliorate the severity of atopic dermatitis. [35, 36] Eczema arises from a combination of factors compromising both the epidermal barrier and the expression of antimicrobial peptides. A VDR agonist was reported to mobilize Foxp3-expressing regulatory $\mathrm{T}$ cells in mice. The same VDR-agonist-treated skin lesions revealed marked increase in antimicrobial peptide expression. There exists, therefore, evidence supporting VDR agonists as a systemic treatment for allergen-triggered eczema. [37] These observations, paired with recent meta-analyses of eczema patients, suggest that vitamin $\mathrm{D}_{3}$ maintains the usual antimicrobial protection that is absent during pathogenesis. [38]

\section{Vitamin D as a Cancer Suppressor}

Ample evidence demonstrates the role of $1 \mathrm{a}, 25(\mathrm{OH})_{2} \mathrm{D}_{3}$ as a marked anticarcinogenic agent. In addition to preserving DNA integrity from oxidative damage and activating apoptotic pathways, it also hinders cell proliferation and promotes differentiation. [39] Unsurprisingly, vitamin $\mathrm{D}_{3}$ deficiency is associated with worsened melanoma-specific incidence, prognosis, and mortality. [40] Many examples illustrate the therapeutic impact vitamin $\mathrm{D}_{3}$ exerts on various skin cancers, primarily through the many signaling pathways it can induce and suppress.

The expression of vitamin D receptor (VDR) declines as pigmented skin lesions progress. According to the results of Brozyna et al, melanocytic nevi already exhibit a sharp drop in the expression of VDR, with levels reduced further as they progressed toward melanomas and metastasis. Importantly, tumor-infiltrating leukocytes maintained high counts of VDR. The authors suggest a linkage between melanocytic lesion progression and the decrease in VDR levels, proposing that VDR expression deteriorates as melanogenesis continues. [41] A later immunohistochemical analysis of 69 cutaneous melanomas further confirmed that VDR expression considerably declined as the cancers progressed. Decreased VDR expression accompanied ulceration and the presence of tumor-infiltrating lymphocytes. Higher VDR levels correlated with less aggressive cases and improved prognoses, a relationship that could help mark cells in histopathological assays. The drop in VDR expression hinders the normal regulatory effects of vitamin $\mathrm{D}_{3}$, and it is this decreased regulatory activity that facilitates tumor growth and permits the progression of disease. [42]

Skin cells synthesize 1a-hydroxylase (CYP27B1), the enzyme that converts serum-25(OH)D to the activated form 1-a, $25(\mathrm{OH})_{2} \mathrm{D}_{3}$. Compared to radial phase tumors and nevi, the more progressed vertical growth phase samples and metastasized melanomas expressed far less CYP27B1 and correlated with shorter survival spans. Additional evidence shows that advanced lesion skin tissues failed to sufficiently produce CYP27B1 as well. Therefore, compromised CYP27B1 serves as a potent gauge of the progression of melanoma. [43]

Perpetually activated in melanoma, transcription factor NF-KB serves as a potent marker to target in cancer treatment. Vitamin $\mathrm{D}_{3}$ suppresses melanoma proliferation, halting NF-KB activity of nonpigmented cells without impacting pigmented cells. The lack or dearth of pigment corresponds with higher NF-KB p65 expression; hence, melanin pigmentation correlates with melanoma resistance to hormone therapy. Vitamin $\mathrm{D}_{3}$ derivatives block the binding of the NF-kB complex to both DNA and NF-kB-dependent reporter assays. Recent progress on $1 a, 25(\mathrm{OH})_{2} \mathrm{D}_{3}$ and its newer hydroxyderivatives are capable of pinpointing NF- $\mathrm{KB}$ to control the progression of nonpigmented melanoma cells. [44]

Compared to normal melanocytes, melanoma cells also increased expression of a different transcription factor, RUNX2. Melanoma cell lines knockout for RUNX2 displayed suppressed Focal Adhesion Kinase (FAK) expression, which consequently hindered growth and mobility. Cholecalciferol, precursor to active vitamin $\mathrm{D}_{3}$, repressed melanoma cell migration by reducing the transcriptional activity of RUNX2, demonstrating another link tying vitamin $\mathrm{D}_{3}$ to carcinoma metastasis. [45]

Another class of compounds that tumor cells manufacture are matrix metalloproteinases, notably MMP-9 and MMP-13, which enhance their growth and promote metastasis. This production is accelerated when cells are exposed to TNF- $\alpha$. The synthetic vitamin D analog calcipotriol suppresses MMP-9 and MMP-13 expression by preventing phosphorylation of their respective p38 and ERK pathways concomitantly. [46]

Constitutive Hedgehog $(\mathrm{HH})$ signaling is active in basal cell carcinoma (BCC) and other tumor growths. Vitamin $\mathrm{D}_{3}$ inhibits $\mathrm{HH}$ signaling by suppressing target gene Gli1 mRNA and also prevents BCC proliferation in vitro and in vivo-a behavior resembling that of cyclopamine, a known $\mathrm{HH}$ signaling inhibitor. A unique aspect of this $\mathrm{HH}$ pathway is how it operates independently of VDR; $\mathrm{HH}$ was still inhibited despite the VDR RNA knockout that prevented the expression of activating 
enzyme 24-hydroxylase. Thus, administering vitamin $\mathrm{D}_{3}$ topically may effectively counter BCC by inhibiting the HH mechanism. [47]

Fibroblast growth factor-2 (FGF-2) is a potent angiogenesis inducer and tumor growth promoter. Its chaperone, heparin-binding protein 17/fibroblast growth factor binding protein-1 (HBp17/FGFBP-1), presents itself as strong cancer biomarker because it is often upregulated in several cancer lines, notably oral squamous cell carcinomas (OSCC). Because HBp17/FGFBP-1 is vital to both FGF activation and its release from the extracellular matrix, the chaperone may also facilitate cancerous angiogenesis. [48] By decreasing levels of HBp17/FGFBP-1, 1a, 25(OH $)_{2} \mathrm{D}_{3}$ prevents the secretion of fibroblast growth factor (FGF-2) from oral squamous carcinoma tissue. This poses remarkable implications for developing drugs against FGF-dependent cancers. [49] The signaling pathways and chemokines vitamin $\mathrm{D}$ induces to counter various autoimmune conditions and cancers are summarized (Table 1).

\section{Treatment}

Despite the range of tumerostatic properties of vitamin $\mathrm{D}$, its high-dose toxicity risk of hypercalcemia renders it an unreliable cancer treatment regimen. Combination therapy using cisplatins and anti-resorptive bisphosphonates has been attempted yet has yielded limited gains. As a result, the search continues for non-calcemic $1,25(\mathrm{OH})_{2} \mathrm{D}_{3}$ analogs that effectively combat cell proliferation. [50]

Assays conducted by Slominski et al delineate the relative calcemic effects and antiproliferative efficiencies of vitamin D-similar secosteroids synthesized by cytochrome P450scc. Analogs $20,23(\mathrm{OH})_{2} \mathrm{D}_{3}, 20(\mathrm{OH}) \mathrm{D}_{3}$, and $1,20(\mathrm{OH})_{2} \mathrm{D}_{3}$, carrying the entire side chain of $1,25(\mathrm{OH})_{2} \mathrm{D}_{3}$, were most effective at arresting cells at the G1/G0 phase. [51] These compounds equipotently stimulated erythroid differentiation in MEL murine leukemia as well as K562 human chronic myeloid cells. Notably, none of the tested hydroxyderivatives significantly induced the expression of CYP24, a major enzyme responsible for inactivating vitamin D. Therefore, P40scc-produced analogs with slower inactivation rates and reduced calcemic activity may unlock new pharmacologically advantageous vitamin D alternatives (Figure 2).

Studies reveal that $1,25(\mathrm{OH})_{2} \mathrm{D}_{3}$ upregulates the production of $\mathrm{p} 21$, a prominent cyclin-dependent kinase inhibitor 1, in squamous carcinoma cells (SCC) on the head and neck regions. Gedlicka et al confirmed that the termination of the cell cycle occurred between G0/G1 phase by demonstrating a clear transformation of hyper-phosphorylated cyclin-CDK complexes to their hypo-phosphorylated conformations in the presence of vitamin $\mathrm{D}_{3}$. [52] MART-10, another vitamin D analog, more potently arrests the cell cycle compared to its parent hormone without effectuating hypercalcemia in vivo. It upregulates genes p21 and p27 while severely downregulating the expression of telomerase. This halt between G0 and G1 phase hinders the growth of squamous carcinoma cells. [53]

Table 1. Summary of immunological impacts of vitamin D and analogs in various diseases.

\begin{tabular}{|c|c|}
\hline Condition & $\begin{array}{l}\text { Immunological role of vitamin } \\
\mathrm{D} / \text { analogs/precursors }\end{array}$ \\
\hline $\begin{array}{l}\text { Lupus } \\
\text { erythematosus }\end{array}$ & $\begin{array}{l}\text { stimulates apoptosis in activated B cells } \\
\text { represses B cell proliferation and immunoglobin } \\
\text { production }\end{array}$ \\
\hline $\begin{array}{l}\text { Asthma and } \\
\text { COPD }\end{array}$ & $\begin{array}{l}\text { reduces prostaglandin (PG)E2 synthesis in lung } \\
\text { fibroblasts } \\
\text { decreases IL-1 } \beta \text {-induced microsomal PGE synthase } \\
\text { (mPGES)-1 expression } \\
\text { stimulate 15-hydroxy PG dehydrogenase, which } \\
\text { degrades PGE2 and terminates the inflammatory } \\
\text { reaction }\end{array}$ \\
\hline Psoriasis & $\begin{array}{l}\text { prevents skin Langerhans cells from stimulating } \\
\text { T-cell proliferation stationed in the skin } \\
\text { blocks synthesis of Th1 chemokines IFN- }- \text {, IL-2, } \\
\text { IL-4, IL-5 }\end{array}$ \\
\hline $\begin{array}{l}\text { Multiple } \\
\text { sclerosis } \\
\text { [murine EAE] }\end{array}$ & $\begin{array}{l}\text { prevents self-reactive T cells from breaching the } \\
\text { CNS without affecting their activation } \\
\text { sustains leukocytosis without inducing } \\
\text { development of T regulatory cells }\end{array}$ \\
\hline $\begin{array}{l}\text { Atopic } \\
\text { dermatitis }\end{array}$ & $\begin{array}{l}\text { upregulates antimicrobial peptide expression } \\
\text { increases Foxp } 3^{+} \text {-expressing T regulatory cell levels }\end{array}$ \\
\hline Melanoma & $\begin{array}{l}\text { suppresses melanoma proliferation } \\
\text { blocks binding of the NF-kB complex to both DNA } \\
\text { and NF-kB-dependent reporter assays } \\
\text { halts NF-kB activity of nonpigmented cells without } \\
\text { impacting pigmented cells } \\
\text { inhibits melanoma cell migration by reducing } \\
\text { transcriptional activity of RUNX2 }\end{array}$ \\
\hline $\begin{array}{l}\text { Squamous } \\
\text { carcinoma }\end{array}$ & $\begin{array}{l}\text { represses secretion of FGF-2, angiogenesis inducer } \\
\text { and tumor promoter } \\
\text { upregulates p21, prominent cyclin-dependent } \\
\text { kinase inhibitor } \\
\text { downregulates expression of telomerase } \\
\text { halts G0/G1 phase } \\
\text { stimulates caspase } 8 / 10 \text {-caspase } 3 \text { apoptosis } \\
\text { mechanism } \\
\text { decreases production of apoptosis inhibitors XIAP } \\
\text { and BIRC2 }\end{array}$ \\
\hline $\begin{array}{l}\text { Basal cell } \\
\text { carcinoma }\end{array}$ & $\begin{array}{l}\text { inhibits HH signaling by suppressing target gene } \\
\text { Gli1 mRNA } \\
\text { *operates independently of VDR, can be } \\
\text { administered topically }\end{array}$ \\
\hline
\end{tabular}




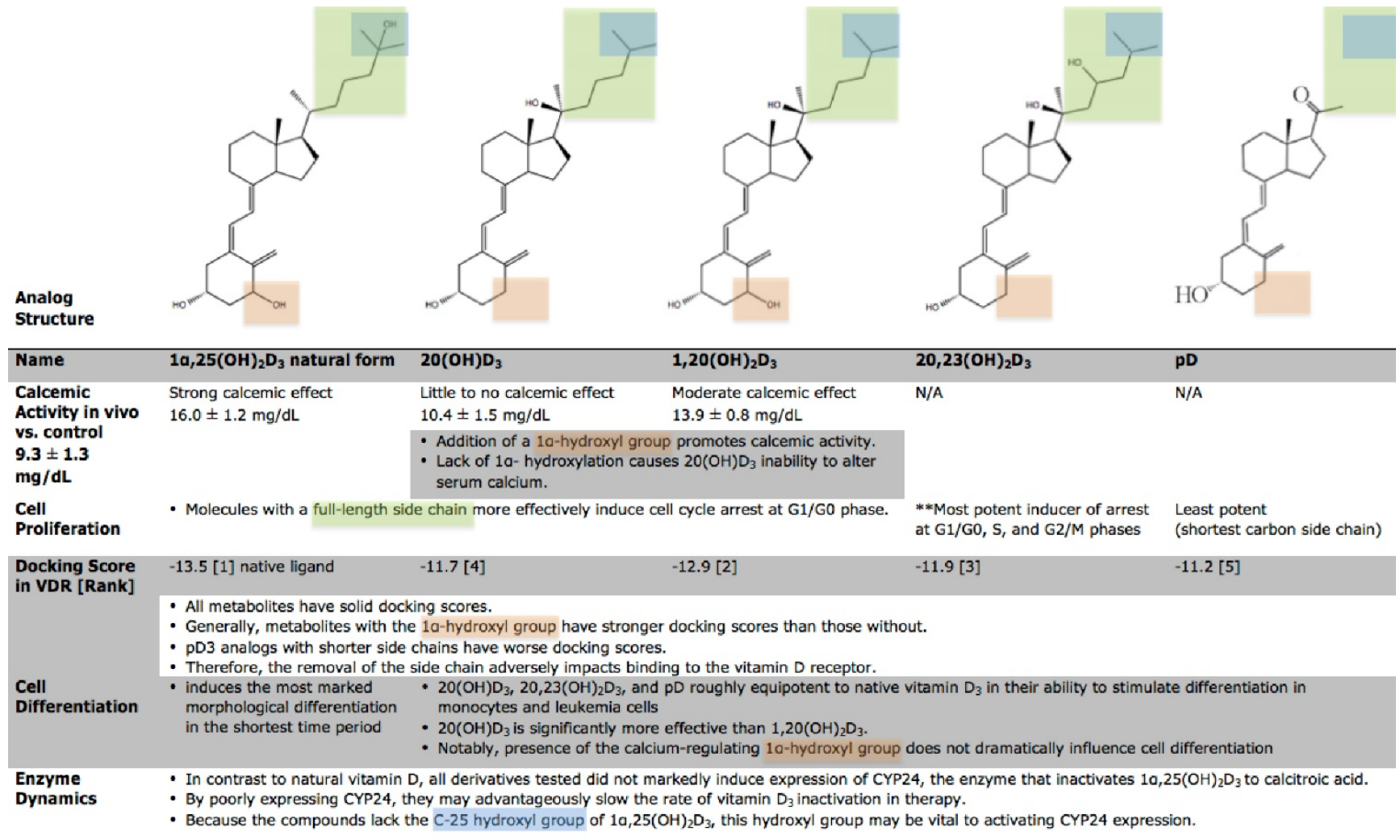

Results from Slominski, A. T., et al. (2010). "Products of vitamin D3 or 7-dehydrocholesterol metabolism by cytochrome P450scc show anti-leukemia effects, having low or absent calcemic activity." PLoS One 5(3): e9907.

Figure 2. Comparable properties of vitamin $\mathbf{D}_{3}$ derivatives. Hydroxyl-derivatives of $1 \alpha, 25(\mathrm{OH})_{2} \mathrm{D}_{3}$ typically produce the same effects as $1 \alpha, 25(\mathrm{OH})_{2} \mathrm{D}_{3}$ in cell differentiation and proliferation using a conserved mechanism across various monocyte, melanoma, and leukemia cell lines. The differences in their functionality can be attributed to their chemical structure. Unlike $1 \alpha, 25(\mathrm{OH})_{2} \mathrm{D}_{3}$, these newly-identified secosteroids demonstrate little to no calcemic activity while preserving their anti-cancer properties. The noticeably low calcemic activity and high effectiveness of $20(\mathrm{OH}) \mathrm{D}_{3}$ warrant it special consideration for future applications in treatment.

A recent study by Spath et al acknowledges the versatility of the different paths vitamin $D_{3}$ implements to manipulate the cell cycle and stunt melanoma growth. Vitamin $\mathrm{D}_{3}$ halted varying melanoma strains in G1 and G2 phase by upregulating and downregulating different cyclins (A1, B1, D1) specific to each individual strain. The findings propose that vitamin $\mathrm{D}_{3}$ recruits a range of regulatory mechanisms across different cell lines that ultimately impair melanoma growth. [54]

Aminolevulinic acid photodynamic therapy (ALA-PDT) can treat a variety of cancers, though it still fails to treat deeper, larger tumors. Evidence reports that pretreating cancerous cells with active vitamin $\mathrm{D}_{3}$ improved ALA-PDT results in mice squamous skin cancer by accelerating post-ALA-PDT apoptosis. [55] The hormone, in low doses, easily enhanced the accumulation of PpIX, the ALA-PDT photosensitizer, and upregulated TNF- $\alpha$ in epithelial tumors concomitantly. Such results broaden the therapy's potential clinical scope.
A different analog, inecalcitol, exhibits marked antitumor behavior. The metabolite prompts apoptosis in a murine model of SCC not only by stimulating the caspase8/10-caspase 3 mechanism but also by attenuating the production of apoptosis inhibitors XIAP and BIRC2. Interestingly, however, such efficiencies vanish in vivo, when inecalcitol doses elicit vitamin D-similar hypercalcemia. Speculation of this phenomenon revolves around inecalcitol's shorter half-life, yet much research remains to be done. [56]

\section{Conclusion}

As demonstrated, the role of $1,25(\mathrm{OH})_{2} \mathrm{D}_{3}$ in immunomodulatory mechanisms is pivotal to normal immune function. The hormone regulates the expression of various pro-inflammatory cytokines, transcription factors, and lymphocyte chemokines. By acting as either a direct anti-inflammatory compound, a transcriptional-regulating receptor complex, or a signaling pathway stimulus, vitamin $\mathrm{D}_{3}$ effectuates a 
broad range of changes with the presence of VDR in a majority of cells. A decrease in the presence of vitamin D receptors correlates with a worsening prognosis and steady progression of melanomas, metastasis, and autoimmune disorders. As our knowledge base elucidates the intricate ways with which vitamin D can shape the innate and adaptive immune responses, we may develop an improved class of treatment derivatives lacking a strong calcemic effect. Clinical evidence demonstrating vitamin $\mathrm{D}^{\prime} \mathrm{s}$ palliative properties continues to gain traction, and effective $1,25(\mathrm{OH})_{2} \mathrm{D}_{3}$ analogs show promise as potential treatment alternatives.

\section{Competing Interests}

The authors have declared that no competing interest exists.

\section{References}

1. DeLuca HF. Overview of general physiologic features and functions of vitamin D. Am J Clin Nutr. 2004; 80: 1689S-96S.

2. Dusso AS, Brown AJ, Slatopolsky E. Vitamin D. Am J Physiol Renal Physiol. 2005; 289: F8-28.

3. Cella M, Engering A, Pinet V, et al. Inflammatory stimuli induce accumulation of MHC class II complexes on dendritic cells. Nature. 1997; 388: 782-7.

4. Penna G, Adorini L. 1 Alpha,25-dihydroxyvitamin D3 inhibits differentiation, maturation, activation, and survival of dendritic cells leading to impaired alloreactive T cell activation. J Immunol. 2000; 164: 2405-11.

5. Griffin MD, Lutz W, Phan VA, et al. Dendritic cell modulation by 1alpha,25 dihydroxyvitamin D3 and its analogs: a vitamin D receptor-dependent pathway that promotes a persistent state of immaturity in vitro and in vivo. Proc Natl Acad Sci USA. 2001; 98: 6800-5.

6. Lemire JM, Archer DC, Beck L, et al. Immunosuppressive actions of 1,25-dihydroxyvitamin D3: preferential inhibition of Th1 functions. J Nutr. 1995; 125: 1704S-1708S

7. Lee Y, Awasthi A, Yosef N, et al. Induction and molecular signature of pathogenic TH17 cells. Nat Immunol. 2012; 13: 991-9.

8. Joshi S, Pantelena LC, Liu XK, et al. 1,25-dihydroxyvitamin $\mathrm{D}(3)$ ameliorates Th17 autoimmunity via transcriptional modulation of interleukin-17A. Mol Cell Biol. 2011; 31: 3653-69.

9. Tang J, Zhou R, Luger D, et al. Calcitriol suppresses antiretinal autoimmunity through inhibitory effects on the Th17 effector response. J Immunol. 2009; 182: 4624-32.

10. Correale J, Ysrraelit MC, Gaitán MI. Immunomodulatory effects of Vitamin D in multiple sclerosis. Brain. 2009; 132: 1146-60.

11. Lemire JM, Adams JS, Sakai R, et al. 1 alpha,25-dihydroxyvitamin D3 suppresses proliferation and immunoglobulin production by normal human peripheral blood mononuclear cells. J Clin Invest. 1984; 74: 657-61.

12. Chen S, Sims GP, Chen XX, et al. Modulatory effects of 1,25-dihydroxyvitamin D3 on human B cell differentiation. J Immunol. 2007; 179: 1634-47.

13. Linker-Israeli M, Elstner E, Klinenberg JR, et al. Vitamin $\mathrm{D}(3)$ and its synthetic analogs inhibit the spontaneous in vitro immunoglobulin production by SLE-derived PBMC. Clin Immunol. 2001; 99: 82-93.

14. Sakaguchi S, Yamaguchi $\mathrm{T}$, Nomura $\mathrm{T}$, et al. Regulatory $\mathrm{T}$ cells and immune tolerance. Cell. 2008; 133: 775-87.

15. Jeffery LE, Burke F, Mura M, et al. 1,25-Dihydroxyvitamin D3 and IL-2 combine to inhibit $\mathrm{T}$ cell production of inflammatory cytokines and promote development of regulatory $\mathrm{T}$ cells expressing CTLA-4 and FoxP3. J Immunol. 2009; 183: 5458-67.

16. Morales-Tirado V, Wichlan DG, Leimeg TE, et al. lalpha,25-dihydroxyvitamin D3 (vitamin D3) catalyzes suppressive activity on human natural regulatory $\mathrm{T}$ cells, uniquely modulates cell cycle progression, and augments FOXP3. Clin Immunol. 2011; 138: 212-221.
17. Gorman S, Geldenhuys S, Judge M, et al. Dietary Vitamin D Increases Percentages and Function of Regulatory $\mathrm{T}$ Cells in the Skin-Draining Lymph Nodes and Suppresses Dermal Inflammation. J Immunol Res. 2016; [Epub 2016 Sep 8]

18. Barrat FJ, Cua DJ, Boonstra A, et al. In vitro generation of interleukin 10-producing regulatory $\mathrm{CD} 4(+) \mathrm{T}$ cells is induced by immunosuppressive drugs and inhibited by T helper type 1 (Th1)- and Th2-inducing cytokines. J Exp Med. 2002; 195: 603-16.

19. Liu X, Nelson A, Wang X, et al. Vitamin D modulates prostaglandin E2 synthesis and degradation in human lung fibroblasts. Am J Respir Cell Mol Biol. 2014; 50: 40-50.

20. Wang Q, He Y, Shen $Y$, et al. Vitamin D inhibits COX-2 expression and inflammatory response by targeting thioesterase superfamily member 4 . J Biol Chem. 2014; 289: 11681-94.

21. Krishnan AV, Feldman D. Molecular pathways mediating the anti-inflammatory effects of calcitriol: implications for prostate cancer chemoprevention and treatment. Endocr Relat Cancer. 2010; 17: R19-38.

22. Haussler MR, Haussler CA, Jurutka PW, et al. The vitamin D hormone and its nuclear receptor: molecular actions and disease states. J Endocrinol. 1997; 154 Suppl: S57-73.

23. Matilainen JM, Räsänen A, Gynther $\mathrm{P}$, et al. The genes encoding cytokines IL-2, IL-10 and IL-12B are primary 1alpha,25(OH)2D3 target genes. J Steroid Biochem Mol Biol. 2010; 121: 142-5.

24. Yu XP, Bellido T, Manolagas SC. Down-regulation of NF-kappa B protein levels in activated human lymphocytes by 1,25-dihydroxyvitamin D3. Proc Natl Acad Sci USA. 1995; 92: 10990-4.

25. Karin M, Lin A. NF-kappaB at the crossroads of life and death. Nat Immunol. 2002; 3: 221-7.

26. Zhang $\mathrm{Y}$, Leung DY, Richers BN, et al. Vitamin D inhibits monocyte/macrophage proinflammatory cytokine production by targeting MAPK phosphatase-1. J Immunol. 2012; 188: 2127-35.

27. Cai Y, Fleming C, Yan J. New insights of T cells in the pathogenesis of psoriasis. Cell Mol Immunol. 2012; 9: 302-9.

28. Lew W, Bowcock AM, Krueger JG. Psoriasis vulgaris: cutaneous lymphoid tissue supports T-cell activation and "Type 1" inflammatory gene expression. Trends Immunol. 2004; 25: 295-305.

29. Kagami S, Rizzo HL, Lee JJ, et al. Circulating Th17, Th22, and Th1 cells are increased in psoriasis. J Invest Dermatol. 2010; 130: 1373-83.

30. Piskin G, Sylva-Steenland RM, Bos JD, et al. In vitro and in situ expression of IL-23 by keratinocytes in healthy skin and psoriasis lesions: enhanced expression in psoriatic skin. J Immunol. 2006; 176: 1908-15.

31. Elloso MM, Gomez-Angelats M, Fourie AM. Targeting the Th17 pathway in psoriasis. J Leukoc Biol. 2012; 92: 1187-97.

32. Dam TN, Møller B, Hindkjaer J, et al. The vitamin D3 analog calcipotriol suppresses the number and antigen-presenting function of Langerhans cells in normal human skin. J Investig Dermatol Symp Proc. 1996; 1: 72-7.

33. Barna M, Bos JD, Kapsenberg ML, et al. Effect of calcitriol on the production of T-cell-derived cytokines in psoriasis. Br J Dermatol. 1997; 136: 536-41.

34. Grishkan IV, Fairchild AN, Calabresi PA, et al. 1,25-Dihydroxyvitamin D3 selectively and reversibly impairs $\mathrm{T}$ helper-cell CNS localization. Proc Natl Acad Sci USA. 2013; 110: 21101-06.

35. Armestajani M, Salehi BS, Vasigh M, et al. Vitamin D supplementation in the treatment of atopic dermatitis: a clinical trial study. J Drugs Dermatol. 2012; 11: 327-30.

36. Samochocki Z, Bogaczewicz J, Jeziorkowska R, et al. Vitamin D effects in atopic dermatitis. J Am Acad Dermatol. 2013; 69: 238-44.

37. Hartmann B, Riedel R, Jörss $\mathrm{K}$, et al. Vitamin D receptor activation improves allergen-triggered eczema in mice. J Invest Dermatol. 2012; 132: 330-6.

38. Kim MJ, Kim SN, Lee YW, et al. Vitamin D Status and Efficacy of Vitamin D Supplementation in Atopic Dermatitis: A Systematic Review and Meta-Analysis. Nutrients. 2016; 8: E789.

39. Schwartz GG, Blot WJ. Vitamin D status and cancer incidence and mortality: something new under the sun. J Natl Cancer Inst. 2006; 98: 428-30.

40. Timerman D, McEnery-Stonelake M, Joyce CJ, et al. Vitamin D deficiency is associated with a worse prognosis in metastatic melanoma. Oncotarget 2016; [Epub ahead of print].

41. Brozyna AA, Jozwicki W, Janjetovic Z, et al. Expression of vitamin D receptor decreases during progression of pigmented skin lesions. Hum Pathol. 2011; 42: 618-31.

42. Brozyna AA, Jozwicki W, Slominski AT. Decreased VDR expression in cutaneous melanomas as marker of tumor progression: new data and analyses. Anticancer Res. 2014; 34: 2735-43. 
43. Brozyna AA, Jozwicki W, Janjetovic Z, et al. Expression of the vitamin D-activating enzyme 1alpha-hydroxylase (CYP27B1) decreases during melanoma progression. Hum Pathol. 2013; 44: 374-87.

44. Janjetovic Z, Brozyna AA, Tuckey RC, et al. High basal NF-kappaB activity in nonpigmented melanoma cells is associated with an enhanced sensitivity to vitamin D3 derivatives. Br J Cancer. 2011; 105: 1874-84.

45. Boregowda RK, Olabisi OO, Abushahba W, et al. RUNX2 is overexpressed in melanoma cells and mediates their migration and invasion. Cancer Lett. 2014; 348: 61-70.

46. Meephansan J, Komine $\mathrm{M}$, Tsuda $\mathrm{H}$, et al. Suppressive effect of calcipotriol on the induction of matrix metalloproteinase (MMP)-9 and MMP-13 in a human squamous cell carcinoma cell line. Clin Exp Dermatol. 2012; 37: 889-96.

47. Tang JY, Xiao TZ, Oda Y, et al. Vitamin D3 inhibits hedgehog signaling and proliferation in murine Basal cell carcinomas. Cancer Prev Res (Phila). 2011; 4:744-51.

48. Begum S, Zhang Y, Shintani T, et al. Immunohistochemical expression of heparin-binding protein 17/fibroblast growth factor-binding protein-1 (HBp17/FGFBP-1) as an angiogenic factor in head and neck tumorigenesis. Oncol Rep. 2007; 17: 591-6.

49. Rosli SN, Shintani T, Toratani S, et al. 1alpha,25(OH)D inhibits FGF-2 release from oral squamous cell carcinoma cells through down-regulation of HBp17/FGFBP-1. In Vitro Cell Dev Biol Anim. 2014; 50: $802-6$.
50. Masuda S, Jones G. Promise of vitamin D analogues in the treatment of hyperproliferative conditions. Mol Cancer Ther. 2006; 5: 797-808.

51. Slominski AT, Janjetovic Z, Fuller BE, et al. Products of vitamin D3 or 7-dehydrocholesterol metabolism by cytochrome P450scc show anti-leukemia effects, having low or absent calcemic activity. PLoS One. 2010; 5: e9907.

52. Gedlicka C, Hager G, Weissenböck M, et al. 1,25(OH)2Vitamin D3 induces elevated expression of the cell cycle inhibitor p18 in a squamous cell carcinoma cell line of the head and neck. J Oral Pathol Med. 2006; 35 : 472-8.

53. Chiang KC, Yeh CN, Hsu JT, et al. MART-10, a novel vitamin D analog, inhibits head and neck squamous carcinoma cells growth through cell cycle arrest at G0/G1 with upregulation of p21 and p27 and downregulation of telomerase. J Steroid Biochem Mol Biol. 2013; 138: 427-34.

54. Spath L, Ulivieri A, Lavra L, et al. Antiproliferative Effects of 1alpha-OH-vitD3 in Malignant Melanoma: Potential Therapeutic implications. Nature Sci Rep. 2017; 7: 40370.

55. Anand S, Wilson C, Hasan T, et al. Vitamin D3 enhances the apoptotic response of epithelial tumors to aminolevulinate-based photodynamic therapy. Cancer Res. 2011; 71: 6040-50.

56. Ma Y, Yu WD, Hidalgo AA, et al. Inecalcitol, an analog of 1,25D3, displays enhanced antitumor activity through the induction of apoptosis in a squamous cell carcinoma model system. Cell Cycle. 2013; 12: 743-52. 